Reprod. Nutr. Dévelop., 1985, 25 (1 B), 275-285.

\title{
Poids et métabolisme des réserves lipidiques au cours de la croissance du chevreau
}

\author{
P. BAS, Annie ROUZEAU, P. MORAND-FEHR
}

Laboratoire de Recherches de la Chaire de Zootechnie, I.N.R.A., Institut National Agronomique Paris-Grignon,

16, rue Claude-Bernard, 75231 Paris Cedex 05

Summary. Weight and metabolism of lipid depots in growing kids.

Adipose tissue growth was studied in two experiments. In the first one, 36 Alpine male kids fed with milk replacer only were slaughtered at 8,14 or $20 \mathrm{~kg}$ (groups A, B and C, respectively). Perirenal adipose tissue developed earlier than omental adipose tissue, but from about 30 days of age, the latter was heavier (allometric coefficients : 2.18 and 1.36 for omental and perirenal adipose tissues, respectively). Even in group $\mathrm{C}$ animals, subcutaneous adipose tissue was scarce.

When expressed in grams of wet tissue, the lipoprotein lipase (LPL) activity of omental adipose tissue decreased with age. This decline was more marked between groups $B$ and $C$ than between groups $A$ and $B(37$ and $14 \%$, respectively). Total LPL activity of omental tissue was 3-fold higher in group $B$ than in group $A$ and 3.7-fold higher in group $C$ than in group $A$. This activity apparently had no relation with the amount of milk intake, daily mean weight gain or omental adipose tissue weight.

In the second experiment, 18 male kids were slaughtered unweaned at 6 weeks or 2 or 14 days after weaning (groups A, B and C, respectively). After weaning, the weight of all adipose tissues decreased. Perirenal adipose tissue weight diminished earlier and more intensively than in the other adipose tissues ( $80 \%$ weight drop in 14 days). The weight loss of omental, pericardiac and mesenteric adipose tissues was 65,49 and $15 \%$, respectively.

As with other lipogenic enzymes, the activity of LPL was highest in omental adipose tissue. In perirenal, pericardiac and mesenteric tissues LPL activity was 30,45 and $60 \%$ less than omental activity. In sternal adipose tissue, LPL activity was very low.

Acetyl CoA carboxylase (ACX) was active in the internal tissues of unweaned kids, but at a low level, i.e. about one-twentieth of that of LPL. Glucose-6-phosphate dehydrogenase (G6PDH) had a higher activity than NADP-malate dehydrogenase (EM). Soon after weaning, all of these enzyme activities dropped sharply. Two days after weaning, LPL activity declined by about $90 \%$ in all tissues, but 14 days after weaning it rose again, especially in perirenal adipose tissue. However, it reached a lower value than in unweaned kids. On the contrary, 14 days after weaning, groupe $\mathrm{C} \mathrm{ACX}$ activity returned to a lower value than that of group $B$.

\section{Introduction.}

Les carcasses de chevreaux de race laitière se caractérisent par une faible proportion de lipides par rapport à celles d'agneaux (Fehr et al., 1976). Mais si les jeunes caprins ont une faible proportion de tissus adipeux intermusculaires, et 
surtout sous-cutanés, en revanche, ceux-ci peuvent présenter une forte proportion de tissus adipeux internes (Bas et al., 1981). Or un état d'engraissement insuffisant et une quantité de gras de couverture trop faible déprécient fortement la valeur commerciale des carcasses de chevreaux (Morand-Fehr et al., 1980).

Ainsi, compte tenu de cette importance économique et du rôle des tissus adipeux en tant que réserve énergétique mobilisable pour courvrir le déficit au cours du sevrage, il semble particulièrement intéressant d'étudier la répartition des dépôts lipidiques, leurs caractéristiques de composition, de lipogenèse et de lipolyse, au cours de la croissance et du sevrage des chevreaux.

Dans ce but, 2 expériences ont été réalisées, l'une pendant la phase lactée (jusqu'à un poids de $20 \mathrm{~kg}$ ) et l'autre autour de la période de sevrage.

\section{Matériel et méthodes.}

Animaux. - Ces deux expériences sont réalisées sur des chevreaux mâles entiers de race Alpine. Ils sont séparés de leur mère immédiatement après le sevrage et mis en case paillée. Les 3 premiers jours, ils reçoivent du colostrum, puis du lait de la mère à volonté en 2 repas chauds et enfin du lait de remplacement comportant 12 puis $15 \%$ d'aliment d'allaitement. Cet aliment contient $18,8 \%$ de matière grasse et $23,4 \%$ de matière azotée.

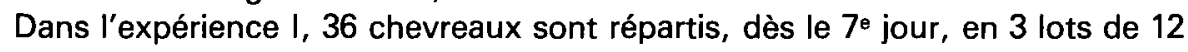
en tenant compte du poids à la naissance, du gain de poids au cours des 6 premiers jours, de la taille de la portée et de leur origine parentale. Ils sont alimentés individuellement, à volonté une fois par jour avec du lait de remplacement à $15 \%$. Les 3 lots (A, B, C) sont abattus vers 9,15 ou $22 \mathrm{~kg}$ de poids vif.

Dans l'expérience II, 18 chevreaux répartis en 3 lots de 6 , équilibrés selon les mêmes critères que dans l'expérience $I$, sont abattus soit non sevrés, soit 2 ou 14 jours après un sevrage brutal à 6 semaines (lots $A, B, C$ ). Ils reçoivent le même lait que dans l'expérience I, mais en outre, du 34e jour à l'abattage, du foin de luzerne et de l'aliment concentré sont distribués à volonté.

Méthodes analytiques. - La teneur en eau des tissus adipeux est obtenue après $48 \mathrm{~h}$ de lyophilisation. La matière grasse est extraite par de l'hexane sous reflux pendant $6 \mathrm{~h}$ à partir de 2 à $3 \mathrm{~g}$ d'échantillon déshydraté puis finement découpé. L'activité de la lipoprotéine lipase (LPL) des tissus adipeux est estimée selon la méthode décrite par Chilliard, Dorléans et Fehr (1977) et celle de l'acétyl CoA carboxylase (ACX) selon celle de Pascal et al., (1977). Les activités de l'enzyme malique (EM) et de la glucose-6-phosphate déshydrogénase (G6PDH) sont estimées respectivement par les méthodes de Hsu et Lardy (1969) et de Ficht, Hill et Chaikoff (1959).

\section{Résultats.}

\section{Expérience /:}

Consommation alimentaire et croissance. - La consommation quotidienne moyenne de lait de remplacement croît de 265 à $310 \mathrm{~g} / \mathrm{j}$ au cours des 15 premiers 
jours de l'expérience. A partir de la $3^{\text {e }}$ semaine elle progresse lentement, pour atteindre $450 \mathrm{~g} / \mathrm{j}$ en $12^{\mathrm{e}}$ semaine. Le gain de poids moyen quotidien (GMQ) diminue avec l'âge, pour se stabiliser à $250 \mathrm{~g} / \mathrm{j}$ vers $6-7$ semaines (tabl. 1). Ce GMO est fortement influencé par la quantité de lait ingérée surtout dans les lots $A$ et $B$ $(r=+0,911, P<1 \%, r=0,841, P<1 \% ; r=0,478$, NS : respectivement pour les lots $A, B$ et $C$ ).

\section{TABLEAU 1}

Performances zootechniques des chevreaux non sevrés. (Expérience I).

\begin{tabular}{|c|c|c|c|c|c|c|}
\hline \multicolumn{2}{|c|}{ Lots } & $\begin{array}{c}\text { Poids vif } \\
\text { à l'abattage } \\
\text { kg }\end{array}$ & $\begin{array}{c}\text { Poids vif }\left(^{*}\right) \\
\text { corrigé } \\
\mathrm{kg}\end{array}$ & $\begin{array}{c}\text { Age } \\
\text { à l'abattage } \\
\text { (j) }\end{array}$ & GMO $\left(^{* *}\right)$ & $\begin{array}{c}\text { Efficacité } \\
\text { alimentaire }\left(^{* * *}\right)\end{array}$ \\
\hline \multirow{2}{*}{ Lot $A$} & $\bar{x}$ & 9,00 & 7,89 & 2,31 & 270 & 0,97 \\
\hline & $\mathrm{CV}$ & 6,3 & 4,9 & 15,9 & 19,1 & 13,5 \\
\hline \multirow{2}{*}{ Lot $B$} & $\bar{x}$ & 15,27 & 13,58 & 48,2 & 249 & 131 \\
\hline & $\mathrm{CV}$ & 3,5 & 3,5 & 12,1 & 8,6 & 5,5 \\
\hline \multirow{2}{*}{ Lot C } & $\bar{x}$ & 22,43 & 19,9 & 77,5 & 251 & 150 \\
\hline & $\mathrm{CV}$ & 5,9 & 5,5 & 8,0 & 10,0 & 9,1 \\
\hline
\end{tabular}

(*) Poids vif corrigé des digesta ; $\left(^{* *}\right)$ GMO : Gain moyen quotidien du 6e jour à l'abattage (pendant la période où l'animal reçoit le lait de remplacement) ; ${ }^{* * *}$ ) Efficacité alimentaire : Quantité de matière sèche consommée par $\mathrm{kg}$ de gain de poids.

$\bar{X}$ : Moyenne calculée sur 12 animaux.

CV : Coefficient de variation.

Développement des tissus adipeux. - Les tissus adipeux sous-cutanés (sternal, caudal, costal) sont peu développés et difficilement quantifiables, même chez les animaux abattus vers $22 \mathrm{~kg}$ (lot $\mathrm{C}$ ). En revanche, les tissus adipeux internes abdominaux (omental, mésentérique et périrénal) sont très importants. L'ensemble des tissus omental et périrénal atteignent jusqu'à $4 \%$ du poids vif corrigé des chevreaux du lot $C$ (Poids vif brut - Poids des digesta) (tabl. 2). Mais, le tissu omental, moins développé que le tissu périrénal à $9 \mathrm{~kg}$ de poids vif, se développe plus rapidement, devenant plus important que le tissu périrénal chez les animaux abattus à 15 et $22 \mathrm{~kg}$. Leurs coefficients d'allométrie respectifs sont de 2,18 et 1,36 .

La corrélation intra-animal entre ces 2 tissus est positive dans les 3 lots, mais elle n'est significative que pour le lot $\mathrm{B}(\mathrm{r}=+0,454 \mathrm{NS}, \mathrm{r}=+0,783 \mathrm{P}<1 \%$ or $r=+0,487 \mathrm{NS}$ respectivement pour les lots $\mathrm{A}$, B et $\mathrm{C}$ ). Le développement de ces tissus ne semble pas influencé par la quantité de lait ingérée puisqu'aux 3 stades d'abattage, les corrélations entre ces 2 paramètres sont très inférieures à 0,2 .

Caractéristiques des tissus adipeux. - Le taux de matière sèche et par conséquent le taux des lipides des tissus $(r>0,99)$ est nettement plus élevé dans les tissus internes que dans les tissus sous-cutanés (tabl. 2). Dans les tissus abdomi- 
TABLEAU 2

Caractéristiques des tissus adipeux de chevreaux. (Expérience 1).

\begin{tabular}{|c|c|c|c|c|c|c|c|c|c|c|c|}
\hline & & & & & \multicolumn{7}{|c|}{ Tissus adipeux } \\
\hline & & \multicolumn{4}{|c|}{ Omental } & \multicolumn{2}{|c|}{ Périrénal } & \multicolumn{2}{|c|}{ Sternal } & \multicolumn{2}{|c|}{ Caudal } \\
\hline & & $\begin{array}{l}\text { Poids } \\
\text { (frais) }\end{array}$ & $\begin{array}{c}\text { MS } \\
\%\end{array}$ & $\begin{array}{c}\text { Lipides } \\
\left({ }^{*}\right)\end{array}$ & $\begin{array}{l}\text { LPL } \\
\left(*^{* *}\right)\end{array}$ & $\begin{array}{l}\text { Poids } \\
\text { (frais) }\end{array}$ & $\begin{array}{c}\text { MS } \\
\%\end{array}$ & $\begin{array}{c}\text { MS } \\
\%\end{array}$ & $\begin{array}{c}\text { Lipides } \\
\left({ }^{*}\right)\end{array}$ & $\begin{array}{c}\text { MS } \\
\%\end{array}$ & $\begin{array}{l}\text { Lipides } \\
\left({ }^{*}\right)\end{array}$ \\
\hline \multirow{2}{*}{ Lot $A$} & $\bar{x}$ & 68 & 75,7 & 72,6 & 580 & 90 & 86,4 & 55,7 & 44,8 & 53,7 & 43,6 \\
\hline & $\mathrm{CV}$ & 20,4 & 8,29 & 10,4 & 22,7 & 26,9 & 1,9 & 11,0 & 16,1 & 6,5 & 9,3 \\
\hline \multirow{2}{*}{ Lot $B$} & $\bar{x}$ & 253 & 84,4 & 82,2 & 498 & 191 & 91,3 & 59,2 & 48,5 & 53,2 & 42,4 \\
\hline & $\mathrm{CV}$ & 32,3 & 3,2 & 4,1 & 23,3 & 19,2 & 1,4 & 14,4 & 22,1 & 11,0 & $\cdot 16,6$ \\
\hline \multirow{2}{*}{ Lot C } & $\bar{x}$ & 459 & 88,7 & 87,2 & 316 & 288 & 92,2 & 55,8 & 43,8 & 55,0 & 43,6 \\
\hline & CV & 19,8 & 2,3 & 2,9 & 29,5 & 19,6 & 1,0 & 10,8 & 17,0 & 10,7 & 14,8 \\
\hline
\end{tabular}

$\left.{ }^{*}\right) \%$ Lipides : Exprimés par rapport à la matière brute du tissu ; $\left({ }^{*}\right)$ LPL : Activité de la lipoprotéine lipase $(e n \mathrm{~nm} / \mathrm{min} / \mathrm{g}$ ).

naux, les teneurs en matière sèche et en lipides croissent avec l'âge alors qu'elles semblent relativement stables dans les tissus externes. Le tissu périrénal est toujours plus riche en matière sèche que le tissu omental, mais cette différence s'atténue avec l'âge.

L'activité de la LPL du tissu omental rapportée au gramme de tissu frais diminue à mesure que le tissu se remplit de lipides $(r=-0,61, P<1 \%$ entre l'activité LPL et le pourcentage de lipides). Cette baisse est plus importante entre 15 et $22 \mathrm{~kg}$ qu'entre 9 et $15 \mathrm{~kg}$ alors que l'on observe le contraire pour l'augmentation des teneurs en matière sèche et en lipides du tissu omental. Toutefois, l'activité totale LPL croît presque à la même vitesse entre 9 et $15 \mathrm{~kg}$ qu'entre 15 et $22 \mathrm{~kg}$ (multipliée par 3 et 3,7 respectivement par rapport au lot A). Lorsqu'elle est rapportée au poids corrigé, cette activité semble avoir atteint un maximum chez les animaux abattus à $13 \mathrm{~kg}$ (lot $\mathrm{B}$ ) puisqu'elle augmente de $75 \%$ entre les lots $A$ et $B$ et qu'elle semble diminuer de $15 \%$ entre les lots $B$ et $C$. L'activité de cette enzyme est aussi indépendante de la quantité moyenne de lait ingérée au cours de toute l'expérience ou même de la dernière semaine $(r<0,3$ pour chaque lot).

\section{Expérience // :}

Consommation alimentaire et variation de poids vif. - La consommation moyenne de matière sèche de lait de remplacement est proche de $500 \mathrm{~g} / \mathrm{j}$ dans les 3 lots au cours des 2 dernières semaines avant le sevrage alors que la consommation de foin et de concentré est négligeable $(<10 \mathrm{~g} / \mathrm{j})$. Le GMO des 12 premiers jours est d'environ $190 \mathrm{~g} / \mathrm{j}$ et de $230 \mathrm{~g} / \mathrm{j}$ au cours des 2 dernières semaines avant le sevrage (tabl. 3 ). 
TABLEAU 3

Performances zootechniques des chevreaux abattus autour du sevrage. (Expérience II).

\begin{tabular}{|c|c|c|c|c|c|c|c|c|c|}
\hline Lots & & $\begin{array}{c}\text { Poids } \\
\text { de } \\
\text { naissance } \\
\text { (kg) }\end{array}$ & $\begin{array}{l}\text { Poids vif } \\
\text { à } \\
\text { l'abattage } \\
\text { (kg) }\end{array}$ & $\begin{array}{l}\text { Poids vif } \\
\text { corrigé } \\
(\mathrm{kg})\end{array}$ & $\begin{array}{c}\text { Age } \\
\text { sevrage }\end{array}$ & $\begin{array}{c}\text { Age } \\
\text { abattage }\end{array}$ & $\underset{\mathrm{g} / \mathrm{j}}{\mathrm{GMO}}$ & $\underset{g / j}{\mathrm{GMO}}$ & $\begin{array}{c}\text { Variation } \\
\text { de } \\
\left.\text { poids } \text { ( }^{* *}\right) \\
\mathrm{g} / \mathrm{j}\end{array}$ \\
\hline \multirow{2}{*}{ Lot $A$} & $\bar{x}$ & 4,57 & 14,40 & 13,42 & - & 43,8 & 189,3 & 237,9 & - \\
\hline & CV & 5,8 & 6,3 & 5,6 & - & 6,3 & 10,8 & 5,5 & - \\
\hline \multirow{2}{*}{ Lot $B$} & $\bar{x}$ & 4,65 & 14,08 & 12,78 & 43,0 & 44,8 & 193,9 & 241,2 & $-216,7$ \\
\hline & $\mathrm{CV}$ & 9,8 & 12,8 & 13,1 & 7,9 & 7,9 & 29,2 & 16,4 & 94,2 \\
\hline \multirow{2}{*}{ Lot C } & $\bar{x}$ & 4,62 & 13,68 & 10,97 & 40,8 & 55,3 & 186,1 & 224,9 & $+24,0$ \\
\hline & $\mathrm{CV}$ & 13,0 & 11,9 & 10,8 & 4,1 & 4,1 & 20,8 & 9,4 & 221,4 \\
\hline
\end{tabular}

(*) GMO : Gain moyen quotidien au cours des 12 premiers jours.

$\left.{ }^{* *}\right)$ GMO : Gain moyen quotidien au cours des 2 dernières semaines avant sevrage.

$\left.{ }^{* * *}\right)$ Variation de poids, du sevrage à l'abattage, en $\mathbf{g} / \mathbf{j}$.

Pendant les 2 jours qui ont suivi le sevrage, les chevreaux perdent environ $200 \mathrm{~g} / \mathrm{j}$. La reprise de leur croissance est lente puisque 3 animaux seulement du lot $C$ dépassent à l'abattage leur poids de sevrage. La consommation de foin et de concentré des animaux du lot $C$ progresse lentement après le sevrage, passant de $100 \mathrm{~g} / \mathrm{j}$ environ le lendemain du sevrage à $380 \mathrm{~g} / \mathrm{j} 14$ jours plus tard.

Développement des tissus adipeux. - A l'âge de 6 semaines, le tissu adipeux interne le plus développé est le tissu omental, puis viennent les tissus périrénal et mésentérique qui sont équivalents en poids, et enfin le tissu péricardique. Mais lorsqu'on considère la quantité de lipides déposés dans chaque tissu, l'écart entre les tissus périrénal et mésentérique devient significatif puisque la quantité de lipides est presque 2 fois plus faible dans le tissu mésentérique que dans le tissu périrénal (tabl. 4).

Quatorze jours après le sevrage (lot $C$ ), tous les tissus adipeux ont diminué en masse et en taux de lipides par rapport au lot $A$ (non sevré). Le tissu périrénal semble plus précocement mobilisé ; deux jours après le sevrage, il a déjà perdu $13 \%$ de son poids, alors que les autres n'ont perdu que moins de $4 \%$. Quatorze jours après le sevrage, $c^{\prime}$ est ce même tissu qui a relativement perdu le plus de poids $(80 \%)$, suivi des tissus omental $(65 \%)$, péricardique $(49 \%)$ et mésentérique $(15 \%)$. Toutefois, la quantité de lipides mobilisés en quatorze jours est légèrement plus importante dans le tissu omental que dans le tissu périrénal 198,4 et $87,1 \mathrm{~g}$ ), le tissu mésentérique n'en ayant perdu qu'environ $42 \mathrm{~g}$. Les autres tissus (péricardique, inguinal et sternal semblent aussi avoir été mobilisés ; néanmoins seule la composition du tissu adipeux sternal n'évolue pas au cours du sevrage).

A côté des tissus adipeux, l'ensemble de la carcasse perd du poids au cours du sevrage (différence de poids : $1,4 \mathrm{~kg}$ soit $20 \%$ entre les lots $A$ et $C$ ). Le foie, 


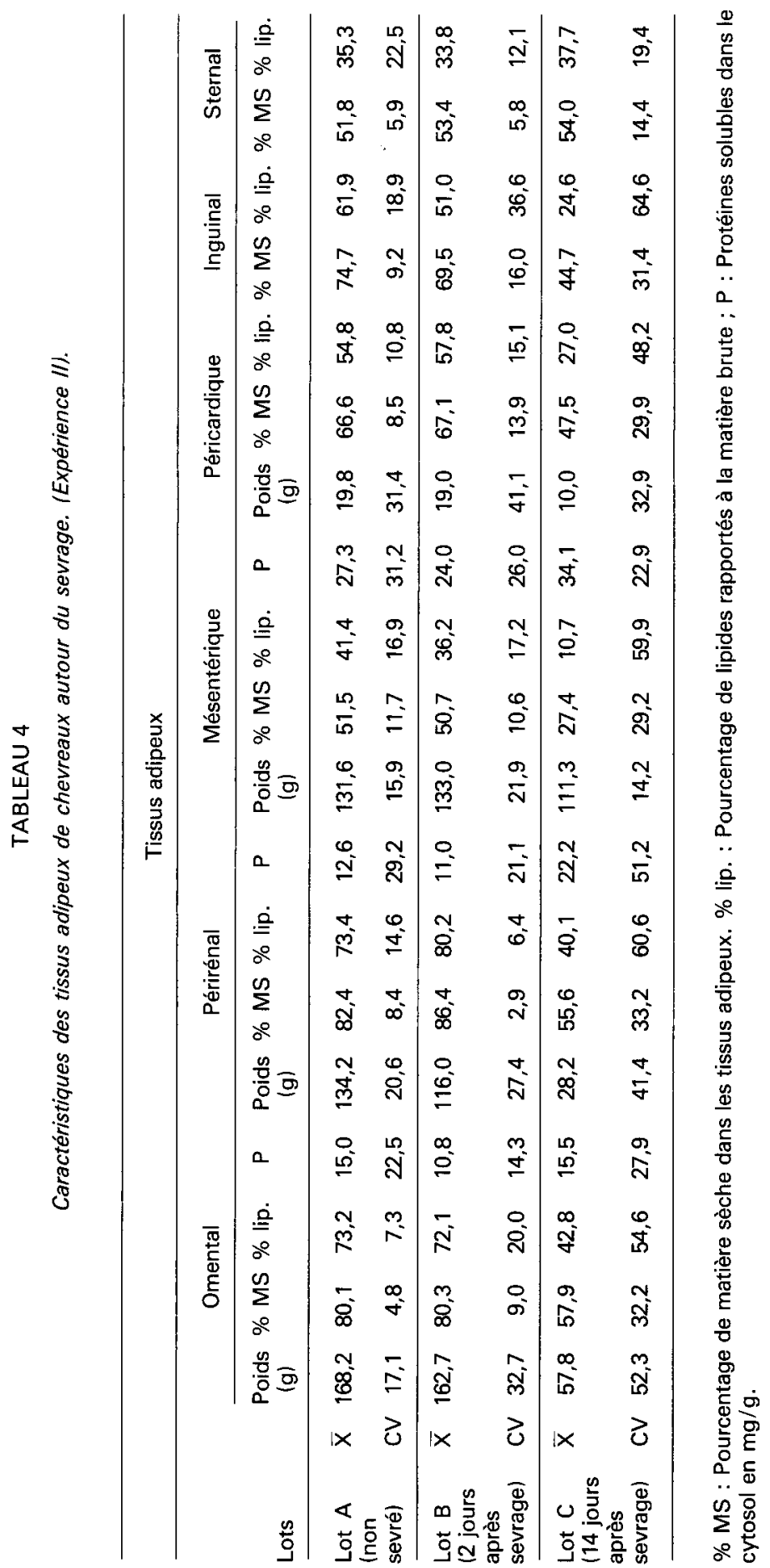


le cœur, les reins perdent aussi respectivement 28,26 et $19 \%$ de leur poids pendant le sevrage, alors que pendant le même temps le poids du rumen vide a doublé (134 et $274 \mathrm{~g}$ pour les lots $\mathrm{A}$ et $\mathrm{C}$ ).

Caractéristiques des tissus adipeux. - A 6 semaines, I'acticité de la LPL du tissu adipeux omental est nettement la plus élevée (tabl. 5). Par gramme de tissu frais, celle du tissu périrénal lui est inférieure d'environ $30 \%$ et celles des tissus péricardique, mésentérique et inguinal de 45 à $60 \%$. Dans le tissu sous-cutané sternal, l'activité de la LPL est très faible (environ $10 \%$ de celle du tissu omental).

Dans les tissus omental et périrénal, l'activité de l'ACX est environ 20 fois plus faible que celle de la LPL et près de 100 fois dans le tissu mésentérique.

Parmi les enzymes liées à la formation de NADPH, utilisable pour la synthèse des acides gras, l'activité de la G6PDH est nettement plus élevée que celle de l'enzyme malique (tabl. 5). L'activité de la G6PDH est plus élevée dans le tissu omental que dans les tissus périrénal et mésentérique. Par contre, l'enzyme malique a une activité comparable dans les tissus omental et périrénal mais supérieure à celle du tissu mésentérique.

Deux jours après le sevrage, l'activité de toutes ces enzymes est fortement diminuée dans tous les tissus adipeux. La chute de ces activités est voisine dans les différents tissus : de 83 à $92 \%$ pour la LPL sauf pour le tissu sternal, 50 à $70 \%$ pour l'ACX, 40 à $55 \%$ pour la G6PDH et de 20 à $50 \%$ pour l'enzyme malique. Elle est généralement plus faible dans le tissu périrénal que dans le tissu omental.

Quatorze jours après le sevrage, l'activité de la LPL a repris sauf dans le tissu mésentérique. Dans le tissu omental, elle a retrouvé $35 \%$ de l'activité existant avant le sevrage et $58 \%$ dans le tissu périrénal. Parmi les autres enzymes, seule I'activité de la G6PDH augmente légèrement dans les tissus périrénal et mésentérique. L'enzyme malique et l'ACX ont des activités, 14 jours après le sevrage, égales ou inférieures à celles mesurées 2 jours après le sevrage.

\section{Discussion.}

Dans ces deux expériences, la croissance des chevreaux a été très élevée. Elle est supérieure à celle enregistrée dans les expériences précédentes (Sauvant, Bas et Morand-Fehr, 1979 ; Bas et al., 1981) et pourrait expliquer en partie l'importance des dépôts lipidiques intra-abdominaux. En effet, le chevreau est considéré comme un animal qui dépose peu de gras au niveau de la carcasse (Fehr et al., 1976). Cependant, il accumule des quantités très importantes de lipides dans ses tissus adipeux intra-abdominaux. Le développement de ces tissus, contrairement à la carcasse, ne semble pas directement lié à la quantité de lait ingéré.

Chaque tissu adipeux a un développement, une composition et un métabolisme qui lui est propre. Parmi les tissus adipeux internes, le tissu périrénal est plus précoce que le tissu omental mais celui-ci croît rapidement et sa masse devient plus importante que celle du tissu périrénal dès l'âge de 30 jours. Des résultats comparables ont été obtenus préalablement sur caprins (Morand-Fehr et 


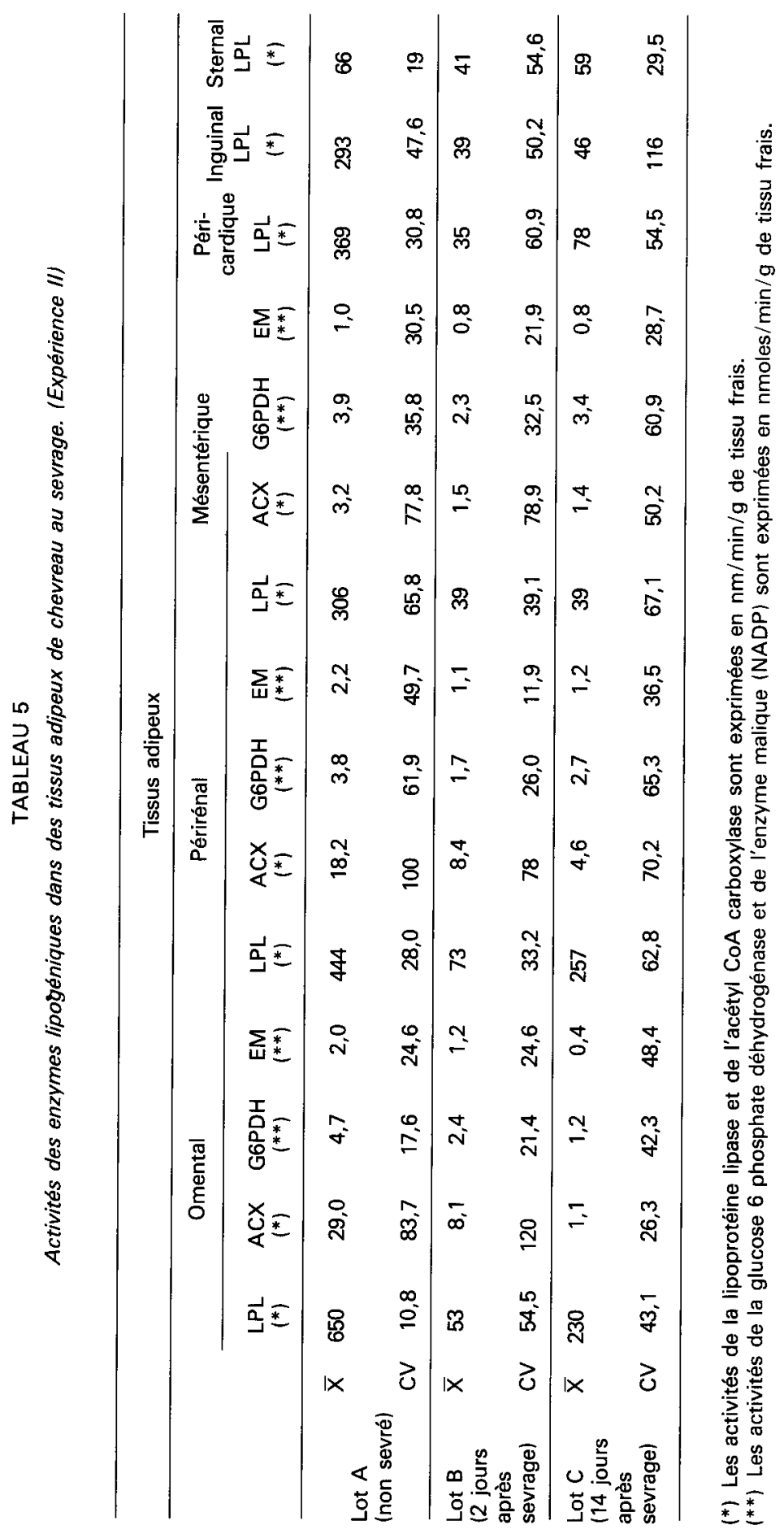


Bas, 1984), et sur ovins (Vézinhet et Prud'hon, 1975) alors que Truscott, Wood et Mac Fie (1983) sur bovins et Jones (1982) sur ovins n'ont pas observé un développement aussi rapide du tissu adipeux omental. La teneur élevée en lipides du tissu adipeux périrénal dès le jeune âge et sa faible augmentation au cours de la croissance permettent de suggérer que chez les caprins, comme chez les ovins et bovins (Broad, Davies et Tan, 1980 ; Robelin, 1981), ce tissu se développe plus par hypertrophie des adipocytes que par hyperplasie.

Les activités des différentes enzymes lipogéniques (quel qu'en soit le mode d'expression) sont toutes plus élevées dans le tissu omental que dans le tissu périrénal (Expérience II).

La lipoprotéine lipase est très active dans tous les tissus adipeux internes mais beaucoup moins dans un tissu externe comme le sternal. Chez ces animaux nourris avec du lait de remplacement, l'activité de l'acétyl CoA carboxylase quoique très faible paraît néanmoins réelle. Les rapports des activités $A C X / L P L$ d'une part et G6PDH/ACX d'autre part, sont voisins dans les tissus adipeux périrénal et omental mais, il n'en est pas de même dans le tissu mésentérique. Le fait que l'enzyme malique soit beaucoup moins active que la glucose 6 phosphate déhydrogénase permet de penser que cette enzyme ne joue qu'un rôle mineur pour fournir l'énergie nécessaire à la synthèse des acides gras et donc que le chevreau non sevré possède déjà des caractéristiques enzymatiques voisines de celles des ruminants. Ce résultat est en accord avec les observations de Liepa, Beitz et Linder (1978) relatives à l'incorporation plus facile d'acétate que de glucose dans les acides gras chez le chevreau non sevré. Le métabolisme des tissus adipeux du chevreau non sevré n'est donc pas comparable à celui des animaux monogastriques.

L'activité optimale, mesurée in vitro, de la LPL n'est peut être pas identique à son activité réelle dans le tissu. Mais, comme son activité n'est liée ni à la quantité des lipides déposés, ni à la quantité de lait ingéré, elle n'est probablement pas un facteur limitant pour le prélèvement des acides gras.

Au cours du sevrage, tous les tissus adipeux ainsi que les activités de leurs enzymes lipogéniques sont fortement réduits mais le tissu périrénal semble être mobilisé en priorité. Des résultats analogues sont observés chez les ruminants à jeûn ou sous restriction alimentaire (Ingle et al., 1973 ; Pothoven et Beitz, 1973, 1975 ; Di Marco, Beitz et Whitehurst, 1981 ; Morand-Fehr et Bas, 1984). Quatorze jours après le sevrage, lorsque l'animal s'est adapté à son alimentation solide, certaines enzymes ont recouvré une grande part de leur activité dans les tissus adipeux. A ce stade, le pourcentage de récupération de l'activité antérieure est le plus élevé pour la LPL et le plus faible pour l'ACX. II est probable que la resynthèse de l'ACX après l'adaptation au régime grossier soit très lente et que par contre, la LPL est ou plus stable ou resynthétisée beaucoup plus rapidement.

\section{Conclusion.}

Ces études soulignent les particularités du métabolisme lipidique du chevreau. Des facteurs nutritionnels qui permettent une croissance rapide comme l'alimentation lactée à volonté, ont favorisé des dépôts lipidiques intraabdominaux, et n'ont eu que peu d'action au niveau des gras sous-cutanés. 
Chaque tissu adipeux a des caractéristiques propres de développement, de composition et de métabolisme.

Avant le sevrage, le développement des tissus adipeux se fait plus par le prélèvement des acides gras exogènes, que par synthèse. Les potentiels d'activités enzymatiques de synthèse semblent plus proches de ceux des ruminants adultes que de ceux des animaux monogastriques.

L'activité LPL mesurée in vitro ne semble pas liée à l'intensité de prélèvement. Elle ne serait donc pas un facteur limitant la lipogenèse avant le sevrage dans les tissus adipeux internes. Toutefois, sa faible activité dans les tissus souscutanés pourrait limiter leur développement.

D'autres moyens (castration, variation de la composition de l'aliment d'allaitement...) peuvent aussi agir sur l'état d'engraissement de l'animal. Mais il reste à préciser, si I'un d'eux pourrait avoir un effet spécifique sur les gras de carcasse par rapport aux tissus adipeux abdominaux afin de permettre une amélioration de l'adiposité de la carcasse.

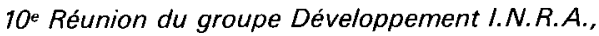
Rennes, 9-10 mai 1984.

Remerciements. - Les auteurs remercient vivement Messieurs G. Durand et G. Pascal et Madame F. Houlier pour leur accueil et leur assistance lors du dosage de l'acétyl CoA carboxylase, de la glucose-6-phosphate déhydrogénase et de l'enzyme malique.

\section{Références}

BAS P., HERVIEU J., MORAND-FEHR P., SAUVANT D., 1981. Facteurs influençant la composition des graisses chez le chevreau de boucherie : Incidence sur la qualité des gras de carcasses, 1, 90-100. In MORAND-FEHR P., BOURBOUZE A., de SIMIANE M., Nutrition and systems of goat feeding. Symp. int., INRA-ITOVIC, Tours-France, 12-15 mai 1981.

BROAD T. E., DAVIES A. S., TAN G.Y., 1980. Pre and Posnatal study of the carcass growth of sheep. 2. The cellular growth of adipose tissues. Anim. Prod., 31, 73-79.

CHILLIARD Y., DORLÉANS M., FEHR P. M., 1977. Mise en évidence d'une activité lipoprotéine lipasique dans le tissu adipeux de chèvre : Comparaison de trois méthodes d'extraction. Ann. Biol. anim. Bioch. Biophys., 17, 107-122.

DI MARCO N. M., BEITZ D. C., WITHEHURST G. B., 1981. Effect of fasting on free fatty acid, glycerol and cholesterol concentrations in blood plasma and lipoprotein lipase activity in adipose tissue of cattle. J. anim. Sci., 52, 75-82.

FEHR P. M., SAUVANT D., DELAGE J., DUMONT B. L., ROY G., 1976. Effect of feeding methods and age at slaughter on growth performances and carcass characteristics of entire young male goats. Livest. Prod. Sci, 3, 183-194.

FICHT W. M., HILL R., CHAIKOFF I. L., 1959. The effect of glucose feeding on glycolytic enzyme activities of the normal rat liver. J. biol. Chem., 234, 1048-1051.

HSU R. Y., LARDY H. A., 1969. Malic enzyme, 18, 230-235. In LOWENSTEIN J. M., Methods in enzymology, Acad. Press, New York, London.

INGLE D. L., BAUMAN D. E., MELLENBERGER R. W., JOHNSON D. E., 1973. Lipogenesis in the ruminant : Effect of fasting and refeeding on fatty acid synthesis and enzymatic activities of sheep adipose tissue. J. Nutr., 103, 1479-1488.

JONES S. D. M., 1982. The accumulation and distribution of fat in ewe and ram lambs. Can. J. anim. Sci., 62, 381-386. 
LIEPA G. U., BEITZ D. C., LINDER J. R., 1978. Fatty acid synthesis in ruminating and non ruminating goats. J. Nutr., 108, 1733-1739.

MORAND-FEHR P., BAS P., 1984. Development and characteristics of adipose tissue in young male goats during growth from birth to weaning. Anim. Prod. (accepté pour publication).

MORAND-FEHR P., SAUVANT D., HERVIEU J., BAS P., 1980. Qualité des carcasses de chevreau : Aspects techniques et commerciaux, In 31e Réun. annu. FEZ, Session 1, Qualité des carcasses d'agneaux et de chevreaux. Münich. RFA, 1-4 septembre 1980.

PASCAL G., DURAND G., MACAIRE J. P., PENOT E., 1977. Evolution de l'activité de l'acétyl-CoA carboxylase et de la lipoprotéine lipase dans le foie et les tissus adipeux du rat mâle au cours du développement après sevrage. Influence du taux des lipides dans la ration. Ann. Biol. anim. Bioch. Biophys., 17, 827-849.

POTHOVEN M. A., BEITZ D. C., 1973. Effect of adipose tissue site, animal weight and long term fasting on lipogenesis in the bovine. J. Nutr., 103, 468-475.

POTHOVEN M. A., BEITZ D. C., 1975. Changes in fatty acid synthesis and lipogenic enzymes in adipose tissue from fasted and fasted-refed steers. J. Nutr., 105, 1055-1061.

ROBELIN J., 1981. Cellularity of bovine adipose tissue : Developmental changes from 15 to 65 percent mature weight. J. Lipid Res., 22, 452-457.

SAUVANT D., BAS P., MORAND-FEHR P., 1979. Production de chevreaux lourds : II. Influence du niveau d'ingestion de lait et du sevrage sur les performances et la composition du tissu adipeux. Ann. Zoot., 28, 73-92.

TRUSCOTT T. G., WOOD J. D., MAC FIE H. J. H., 1983. Fat deposition in Hereford and Friesian steers. 1. Body composition and partitioning of fat between depots. J. agric. Sci., Camb., 100, 257-270.

VÉZINHET A., PRUD'HON M., 1975. Evolution of various adipose deposits in growing rabbits and sheep. Anim. Prod., 20, 363-370. 